\title{
Sheathless separation of microalgae from bacteria using a simple straight channel based on viscoelastic microfluidics
}

Dan Yuan ${ }^{\mathrm{a}}$, Qianbin Zhao ${ }^{\mathrm{a}}$, Sheng Yan ${ }^{\mathrm{d}}$, Shiyang Tang ${ }^{\mathrm{a}}$, Yuxin Zhang ${ }^{\mathrm{a}}$, Guolin Yun ${ }^{\mathrm{a}}$, Nam-Trung Nguyen ${ }^{b}$, Ronald Sluyter ${ }^{\mathrm{e}, \mathrm{f}}$, Jun Zhang ${ }^{\mathrm{b}, *}$, Ming Li ${ }^{\mathrm{c}, *}$ and Weihua Lia,*

${ }^{a}$ School of Mechanical, Materials, Mechatronic and Biomedical Engineering, University of Wollongong, Wollongong, NSW 2522, Australia

${ }^{b}$ Queensland Micro and Nanotechnology Centre, Griffith University, Brisbane QLD 4111, Australia

${ }^{c}$ School of Engineering, Macquarie University, Sydney, NSW 2122 Australia

${ }^{d}$ Department of Chemistry, University of Tokyo, Tokyo, Japan

${ }^{e}$ School of Biological Sciences, University of Wollongong, Wollongong, NSW 2522, Australia fIllawarra Health and Medical Research Institute, Wollongong, NSW 2522 Australia

${ }^{*}$ Corresponding authors: weihuali@uow.edu.au

jun.zhang@griffith.edu.au

ming.li@mq.edu.au 


\begin{abstract}
Microalgae cells have been recognized as a promising way to meet the world's growing demands for renewable energy, food, livestock feed, water, cosmetics, pharmaceuticals, and materials. In order to ensure high efficiency and quality of the production of biomass, biofuel, or bio-based products, purification procedures prior to the storage and cultivation of the microalgae from the contaminated bacteria are of great importance. This work proposed and developed a simple, sheathless, and efficient method to separate microalgae Chlorella from bacteria Bacillus Subtilis in a straight channel based on the viscoelasticity of medium. The microalgae and bacteria migrate differentially to the channel centre and channel walls respectively. Fluorescent microparticles with $1 \mu \mathrm{m}$ and $5 \mu \mathrm{m}$ diameters were first used to mimic the behaviours of bacteria and microalgae to optimize the separating conditions. Then the comparison experiments in Newtonian fluid and in viscoelastic fluid in straight channel with different aspect ratios were demonstrated. At the optimal condition, removal ratio for $1 \mu \mathrm{m}$ microparticles and separation efficiency for $5 \mu \mathrm{m}$ particles is as high as $98.28 \%$ and $93.85 \%$ respectively. For bacteria and microalgae cells separation, separation efficiency is $92.69 \%$ and $100 \%$ respectively. This work demonstrated continuous separation of microalgae from bacteria for the first time by viscoelastic microfluidics. This technique can also be applied as separating technique for cultures of mammalian cells or other kind of cells.
\end{abstract}

Keywords: Viscoelastic microfluidics, differential viscoelastic separation, microalage, bacteria 


\section{Introduction}

Particle or cell separation in a continuous and label-free manner is essential in a wide range of applications such as disease diagnostics, chemical and biological analysis, microalgae biotechnology, and environmental assessment [1-4]. Centrifugation and filtration are two conventional separation methods. However, the centrifugation method is time-consuming, labour-intensive and may impair the analytes of interest due to the mechanical stress induced by high speed rotation. In addition, filter clogging is an inherent problem which is often difficult to avoid [5].

Recently, microfluidic-based techniques have emerged as efficient and powerful tools for particle/cell manipulation due to their unique advantages of lower cost, reduced sample volume needed, high efficiency and accuracy $[6,7]$. According to the operation principle, these microfluidic techniques can be classified as either active or passive methods. Active methods use external forces such as acoustic [8], dielectrophoretic (DEP) [9, 10], optical [11] and magnetic [12] forces for operation, whereas passive methods are simply based on the geometrical effects of microchannels and hydrodynamic forces, such as pinched flow fractionation [13], inertial microfluidics [14-16], deterministic lateral displacement [17], microfiltration [18] and hydrophoresis [9, 19]. However, most of these manipulating methods have been performed and studied in Newtonian fluids. The particle migration based on viscoelastic fluid has attracted increasing attention due to its superior focusing performance and simpler channel design [20-32]. Compared with particle migration in a Newtonian fluid, in a viscoelastic fluid, 3D particle focusing can be easily realized in simple straight channels without any external force fields or complex microchannel structure. Besides, this technique can manipulate particles with a much wider size range (from submicrometer to even nanometer) [33-36]. These advantages of viscoelastic fluids allow fast growth of microfluidic applications based on viscoelastisity-induced particle migration [37, 38]. 
Microalgae cells, which are unicellular organisms, typically found in freshwater and marine systems. Recently, they have raised great concern from both industry and academia. They contain chlorophyll and other pigments that trap light from the sun, and convert the light energy into some form of carbohydrate in a process called photosynthesis. Microalgae has many superior capabilities, such as high growth rate [39], high-efficiency biofuel production [40], growth on non-arable land without competing with agriculture [41], production of valuable co-products after oil extraction [42], treatment of wastewater [43], and bio-fixation of carbon dioxide $\left(\mathrm{CO}_{2}\right)$ with respect to air quality improvement [44]. Therefore, microalgae has been recognized as a promising way to meet the world's growing demands for renewable energy, food, livestock feed, water, cosmetics, pharmaceuticals, and materials. Over the past several years, microfluidic platforms have been used for research on microalgae on a variety of topics [4], such as cell identification [45, 46], on-chip detection of microalgal cells [47-49], cell sorting [50, 51], cell culturing [52-54], cell disruption [55, 56], harvesting $[57,58]$ and microbial bioenergy applications [59, 60].

However, one of the major issues threatening microalgae research and production is the potential contamination by bacteria during microalgae collection and cultivation. To ensure high efficiency and quality of the production of biomass, biofuel, or bio-based products, purification procedures prior to the storage and cultivation of the microalgae to separate them from the undesired bacteria are indispensable. Traditional methods to mitigate contaminations include centrifugation and filtration [61], flow cytometer [62], culturing on a selective medium in agar plates [63], micropipetting [64] or serial dilution [65]. These traditional methods face the limitations of laborious, high cost, or damage on cell intactness. Rare works utilizing microfluidic technology to tackle this challenge, only Neus et al. [66] and Maira et al. [67] have performed purification of microalgae from contaminates using inertial microfluidics. Neus et al. utilised a straight channel with the aid of sheath flow to purify green algae Coenochloris 
signiensis from bacteria cells, while Maira et al. used a straight microchannel with a slanted cross-section shapes to purify Tetraselmis suecica from a common invading diatom, Phaeodactylum tricornutum. Both works were conducted in the Newtonian medium.

In this work, we will employ the unique viscoelasticity of medium to separate and purify microalgae from bacteria using a simple straight channel without the aid of sheath flow. By adding a small amount of biocompatible polymers into the cell culture medium, separation of microalgae from bacteria with high removal ratio and high separation efficiency can be realized. Microalgae cells migrate towards the channel walls, while the bacteria migrate to the center of the channel based on the differential viscoelastic migration [25, 34]. The separating scheme is dependent on the different blockage ratios of microalgae cells and bacteria (blockage ratio $\beta=a / D_{\mathrm{h}}$, where $D_{h}=2 w h /(w+h)$ is the hydraulic diameter for a rectangular channel with $w$ and $h$ representing the width and height of the channel cross section). If the blockage ratio $\beta$ is below 0.25 , particles/cells are prone to be focused at the centerline of the channel. However, if the blockage ratio $\beta$ is above 0.25 , the particles/cells will be pushed towards the sidewalls, because the normal stresses is strengthened by the effect of the blockage and the centerline of the channel is no longer a stable equilibrium position [68, 69]. In this way, particles/cells with blockage ratio below $\beta=0.25$ and above $\beta=0.25$ will migrate differentially to centerline and sidewalls of the channel regardless of their initial positions. Prior to separation of microalgae and bacteria, fluorescent microparticles with $1 \mu \mathrm{m}$ and $5 \mu \mathrm{m}$ diameters were used to optimize the separating conditions. And the effects of fluid viscoelasticty and channel aspect ratio were studied experimentally. Then the microalgae Chlorella sample containing bacteria Bacillus Subtilis was used to test the performance of the proposed device. This work is the first study to utilize viscoelastic microfluidics for separation of microalgae from bacteria. We expect this work will be of interest to both the scientific community of microfluidics and the phycology. 


\section{Theory}

\section{Inertial lift force}

In Newtonian fluid, the shear gradient lift force and wall lift force are the two dominant forces to govern the particle migration, and equilibrium positions are created by the balance of the two lift forces. The sum of the two inertial lift forces, which is called the net inertial lift force, can be expressed as [70, 71]:

$$
\begin{gathered}
F_{L}=\frac{\rho_{f} U_{m}^{2} a^{4}}{D_{h}^{2}} f_{L}\left(R_{c}, x_{c}\right) \\
R_{c}=\frac{\rho_{f} U_{m} D_{h}}{\mu_{f}}=\frac{2 \rho_{f} Q}{\mu_{f}(w+h)}
\end{gathered}
$$

where $\rho_{f}, U_{m}$ and $\mu_{f}$ are the fluid density, mean velocity, and dynamic viscosity, respectively; $a$ is the spherical diameter of the particles; $Q$ is the volumetric flow rate. The lift coefficient of net inertial lift force $f_{L}\left(R_{c}, x_{c}\right)$ is a function of the position of the particles within the cross section of channel $x_{c}$ and the channel Reynolds number $R_{c}$ [71].

\section{Elastic force}

In viscoelastic fluid, the polymer within the medium can induce an additional elastic force on particles. $W_{i}$ was used to characterize the elastic effects of the viscoelastic fluid, which is the ratio of two time constants [21]:

$$
W_{i}=\frac{\lambda}{t_{f}}=\lambda \&=\lambda \frac{2 V_{m}}{w}=\frac{2 \lambda Q}{h w^{2}}
$$

where $\lambda$ is the relaxation time of the fluid, and $V_{m}$ and $t_{f}$ is the average velocity and characteristic time of the channel flow, respectively. The characteristic time is $2 V_{m} / w$ or $2 \lambda Q / h w^{2}$ in a rectangular channel. In viscoelastic fluids, both the first normal stress $N_{1}$ $\left(=\tau_{x x}-\tau_{y y}\right)$ and the second normal stress $N_{2}\left(=\tau_{y y}-\tau_{z z}\right)$ contribute to particle migration. $\tau_{x x}$, $\tau_{y y}$, and $\tau_{z z}$ are normal stresses that are exerted along the main flow, the velocity gradient and 
vorticity direction, respectively. However, the effects of $N_{2}$ can be neglected in the diluted polyethylene oxide (PEO) solutions [72, 73], because $N_{1}$ is much larger than $N_{2}$. The elastic force $F_{E}$, which originates from an imbalance in the distribution of $N_{1}\left(=\tau_{x x}-\tau_{y y}\right)$ over the size of the particle, can be expressed as [74]:

$$
F_{E}=C_{e L} a^{3} \nabla N_{1}=C_{e L} a^{3}\left(\nabla \tau_{x x}-\nabla \tau_{y y}\right)=-2 C_{e L} a^{3} \eta_{p} \lambda \nabla \&^{2}
$$

where $C_{e L}$ is the non-dimensional elastic lift coefficient, $a$ is the particle size, and $\eta_{p}$ is the polymeric contribution to the solution viscosity.

\section{Working mechanism}

The microfluidic device for separation of microalgae and bacteria is a straight channel with aspect ratio being $3(w / h=3)$. Figure 1 shows the schematic illustration of the separation principle (top view). The inlet solution is the microalgae sample containing bacteria with PEO dissolved. The blockage ratio of the microalgae $(\beta=0.33)$ is above 2.5 . When they were displaced from the centerline, the fluid tends to flow through the larger gap between the particles and the wall. Therefore, the enhanced compressive normal stress at the near center side will drive them towards the sidewalls $[68,69]$. Whereas, for the smaller bacteria $(\beta=0.07)$, the effect of the blockage ratio is small, and particles will migrate to centerline of the channel regardless of their initial positions under the elasto-inertial effects [21]. Therefore, at the inlet section, the microalgae and bacteria are dispersed randomly. Based on the size-based differential viscoelastic focusing, after a certain length, the microalgae slowly migrate to the channel wall in a focused state, while the bacteria focused to the channel centreline. At the end of the straight channel, three bifurcating branches will collect corresponding microalgae cells and bacteria cells respectively. 


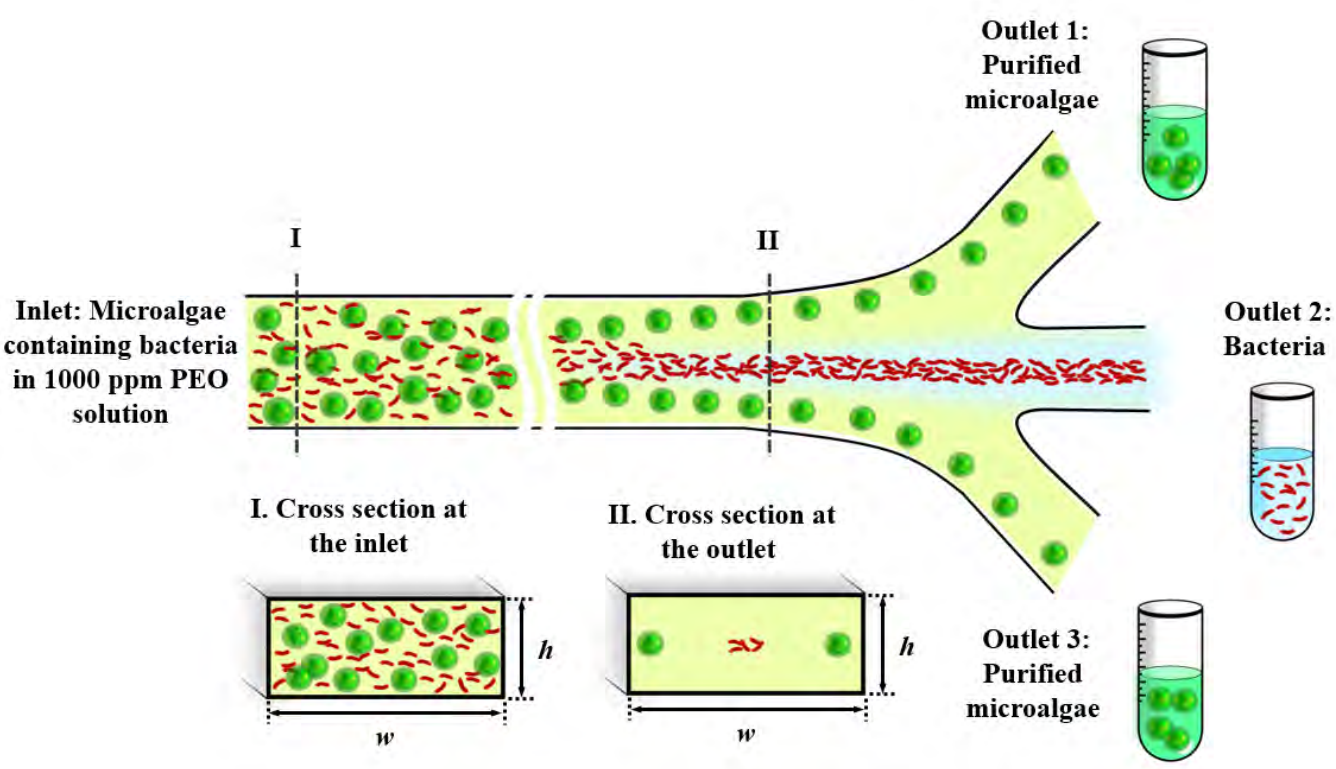

Figure 1 Schematic representation of the separation principle (top view) with $w$ being the width of the channel, $h$ its height. The inlet solution is the PEO dissolved microalgae sample containing bacteria. The green particles represent the microalgae chlorella, while the red rod-shaped particle represents the bacteria bacillus subtilis. Based on the size-based differential viscoelastic focusing, the microalgae cells move to the channel wall, while the bacteria move to the channel centre. At the end of channel, a purified sample containing only microalgae can be recovered from outlet 1 and outlet 3 .

\section{Materials and methods}

\section{Design and fabrication of a microfluidic device}

Standard photolithography and soft lithographic techniques were used to fabricate the following devices $[75,76]$. Straight channels with three different aspect ratios $(A R=3,5,10)$ were fabricated. Their depth was fixed at $10 \mu \mathrm{m}$. The channel with aspect ratio 3 was chosen to separate microalgae cells and bacteria. The channel with aspect ratios of 5 and 10 were used for comparison experiments.

\section{Preparation of the PEO medium}

For microparticle separation, PEO (2,000,000 Da; Sigma-Aldrich) was dissolved in deionized water (DI water) with a concentration of 1000 parts per million (ppm) to form the viscoelastic fluid. For comparisons, DI water was used as the Newtonian fluid. Tween 20 (Sigma-Aldrich) was added to DI water with volume ratio of $0.01 \%(\mathrm{v} / \mathrm{v})$ to prevent particle aggregation. 
For microalgae and bacteria separation, PEO was dissolved in DI water with a concentration of $2000 \mathrm{ppm}$, then the cultured microalgae sample containing bacteria was mixed with 2000 ppm PEO solution with the volume ratio of 1:1 to obtain the $1000 \mathrm{ppm}$ PEO.

\section{Particle and cell preparation}

For particle separating experiments, particle suspensions were prepared by diluting $1 \mu \mathrm{m}$ internally red dyed fluorescent polystyrene microspheres (Thermo Fisher Scientific, CV5\%) and $5 \mu \mathrm{m}$ internally green dyed fluorescent polystyrene microspheres (Thermo Fisher Scientific, CV5\%) in the 1000 ppm PEO medium.

For cell and bacteria separation, a mixed culture of Chlorella and Bacillus Subtilis was used. Chlorella cells are single celled, non-motile green algae, obtained from Southern Biological, Australia, with average diameters of approximately $5 \mu \mathrm{m}$. Bacillus Subtilis are mobile and rod-shaped, and is a common source of environmental contamination in the laboratory. Chlorella cells were cultured autotrophically in $50 \mathrm{ml}$ tubes with open caps using CM3 Chlorella Culture medium (Southern Biological). The cultures were exposed to a continuous light provided by a fluorescent lamp, and incubated at a constant temperature of $30{ }^{\circ} \mathrm{C}$. The cultures were shaken daily by an orbital shaker to ensure nutrients homogeneity and agglomerates dispersion. After culturing 4 weeks, the co-cultured sample was input to the microchannel for testing.

\section{Experimental setup}

The sample suspension was infused into the microfluidic device by a $1 \mathrm{ml}$ syringe. The flow rate was controlled by a syringe pump (Legato 100, Kd Scientific, USA). An inverted microscope (CKX41, Olympus, Japan) mounted with a CCD camera (Optimos, Q-imaging, Australia) was used to observe and capture images of the fluorescent particles, cells and fluids. The fluorescent images were post-processed and analysed with Q-Capture Pro 7 (Q-imaging, Australia) software. 


\section{Results and discussion}

\section{Effect of flow rates and channel length}

Fluorescent microparticles with $1 \mu \mathrm{m}$ and $5 \mu \mathrm{m}$ diameters were first used to mimic the behaviour of microalgae and bacteria to optimize the separating conditions. Flow rates were tested from $Q=0.01$ to $Q=20 \mu \mathrm{l} / \mathrm{min}$. Trajectories of $1 \mu \mathrm{m}$ and $5 \mu \mathrm{m}$ fluorescent microparticles in viscoelastic fluid in straight microchannel with $A R=3$ are shown in Figure 2 (a). At a low flow rate $(Q=0.01 \mu \mathrm{l} / \mathrm{min})$, the $5 \mu \mathrm{m}$ microparticles focused well along two sidewalls of channel due to the larger blockage ratio, and $1 \mu \mathrm{m}$ microparticles started to migrate to the centre of the channel because of elasto-inertial effect and negligible effect of blockage ratio. As the flow rate increases $(Q=0.1 \mu \mathrm{l} / \mathrm{min}$ and $1 \mu \mathrm{l} / \mathrm{min}), 1 \mu \mathrm{m}$ microparticles are progressively tightly focused at the centre of the channel, and $5 \mu \mathrm{m}$ microparticles remain focused status. When the flow rate increases further $(Q \geq 5 \mu \mathrm{l} / \mathrm{min})$, as the inertial effect starts to be dominant, the $1 \mu \mathrm{m}$ microparticles become dispersed again, and the two focusing lines of $5 \mu \mathrm{m}$ microparticles migrate towards the channel centre and become a single focusing line. The optimum flow rate for separation of $1 \mu \mathrm{m}$ and $5 \mu \mathrm{m}$ fluorescent microparticles is $Q=1 \mu \mathrm{l} / \mathrm{min}$. It's distinct that there is a maximum lateral gap between $1 \mu \mathrm{m}$ and $5 \mu \mathrm{m}$ microparticles at the flow rate of $Q=1 \mu \mathrm{l} / \mathrm{min}$, indicating an optimal separation of $1 \mu \mathrm{m}$ and $5 \mu \mathrm{m}$ microparticles, Figure 2(c).

The effect of channel length was investigated by observing the trajectories of the $1 \mu \mathrm{m}$ and $5 \mu \mathrm{m}$ fluorescent microparticles at the inlet, $1 \mathrm{~cm}$ from inlet, $2 \mathrm{~cm}$ from inlet, and outlet at the flow rate of $1 \mu \mathrm{l} / \mathrm{min}$, Figure 2 (b). At the inlet, the particle mixture are dispersed, and along the channel length, the $1 \mu \mathrm{m}$ microparticles become gradually focused at the channel centre, while the $5 \mu \mathrm{m}$ microparticles migrated to the channel sidewalls, enabling complete separation at the outlet. Besides, the lateral position gap between $1 \mu \mathrm{m}$ and $5 \mu \mathrm{m}$ microparticles increases along the channel length, Figure 2(d). 
(a)
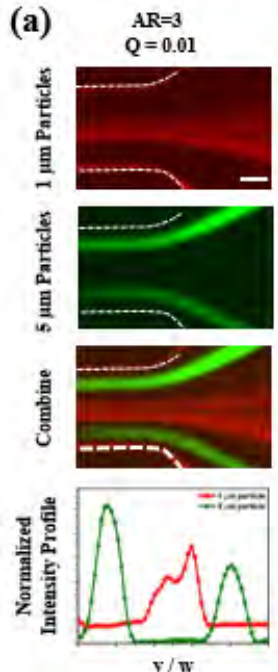

(b)
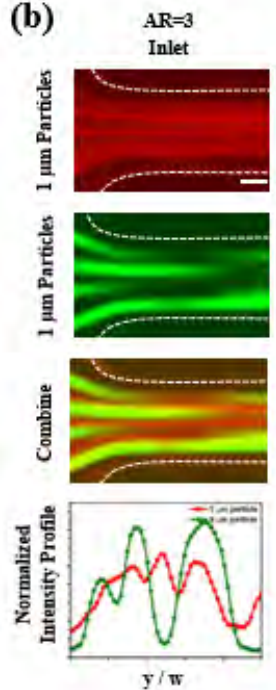
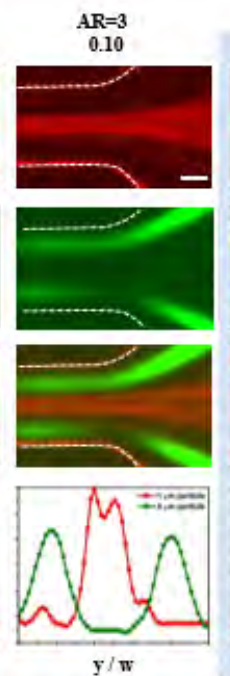

$A R=3$
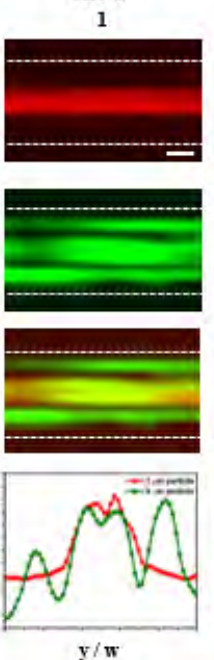

$\mathrm{AR}=3$
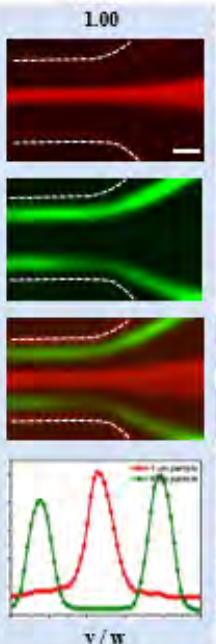

$A R=3$

2
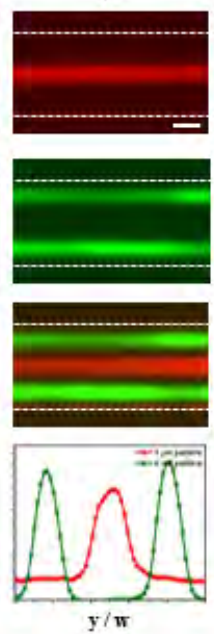
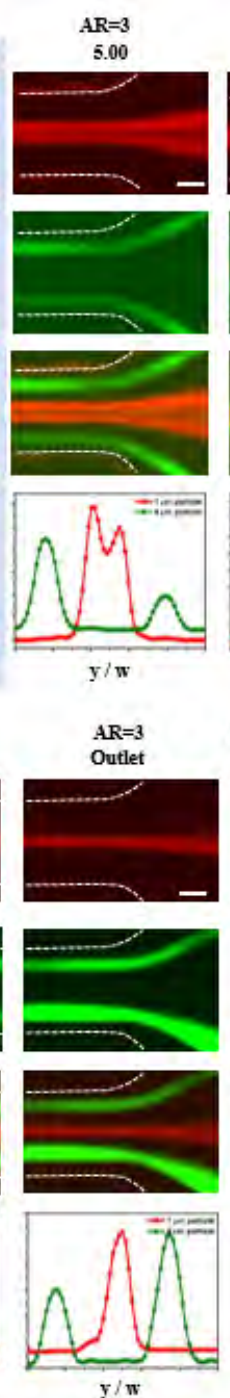
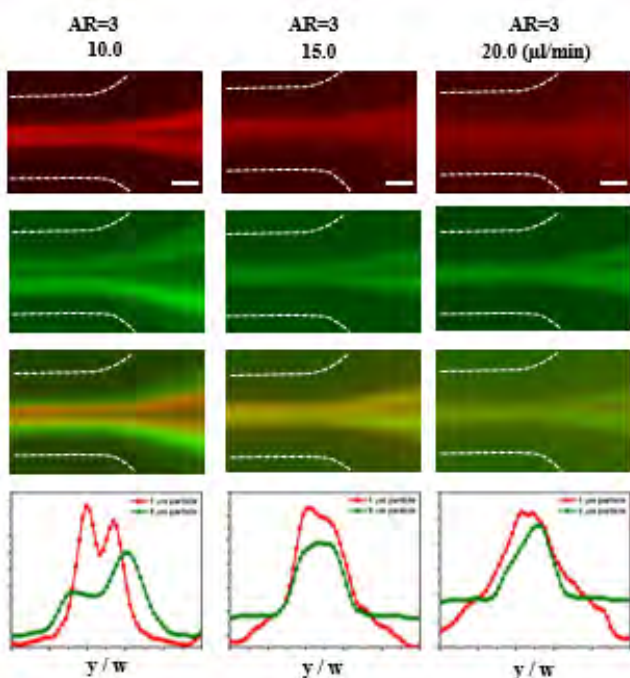

(c)

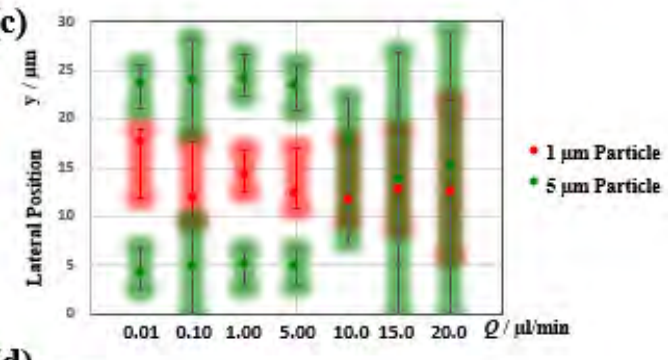

(d)

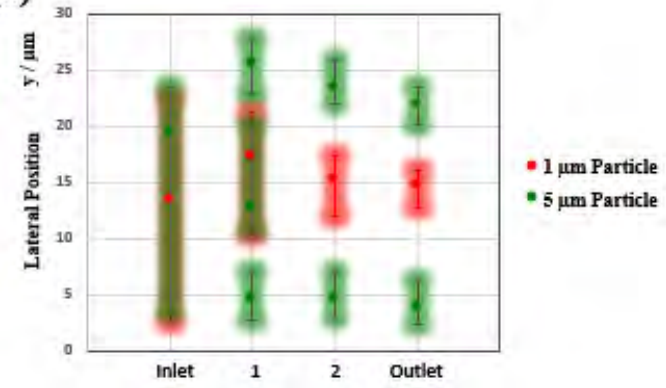

Figure 2 Trajectories of the 1 and $5 \mu \mathrm{m}$ fluorescent microparticles in viscoelastic fluid in straight microchannel with $A R=3$. (a) Trajectories of the fluorescent microparticles at the outlet of the straight microchannel at flow rates ranging from 0.01 to $20 \mu \mathrm{l} / \mathrm{min}$. The first and second rows are the individual fluorescent trajectories of $1 \mu \mathrm{m}$ and $5 \mu \mathrm{m}$ particles. The third row is combined fluorescent trajectories of both microparticles. The fourth row is their normalized intensity profiles. (b) Trajectories of the fluorescent microparticles, and their normalized intensity profiles at the inlet, $1 \mathrm{~cm}$ from inlet, $2 \mathrm{~cm}$ from inlet, and outlet. Flow rate is $1 \mu \mathrm{l} / \mathrm{min}$. (c) Equilibrium positions for $1 \mu \mathrm{m}$ and $5 \mu \mathrm{m}$ fluorescent microparticles at outlet of the microchannel are plotted as a function of different flow rates. (d) Equilibrium positions for $1 \mu \mathrm{m}$ and $5 \mu \mathrm{m}$ fluorescent microparticles are plotted as a function of different positions at the flow rate of $1 \mu \mathrm{l} / \mathrm{min}$. The dots represent the lateral positions of peak fluorescence, the error bars indicate the lateral range within which the particle fluorescence drop to $70 \%$. Note that the best flow rate for the fractionation of particles is $Q=1 \mu \mathrm{L} / \mathrm{min}$. The scale $=10 \mu \mathrm{m}$.

\section{Effect of fluid elasticity}


To investigate the fluid elasticity on particle migration, experiments were also carried out in Newtonian fluid. Figure 3 shows trajectories of the $1 \mu \mathrm{m}$ and $5 \mu \mathrm{m}$ fluorescent microparticles in Newtonian fluid in straight microchannel with $A R=3$ at flow rates ranging from 0.01 to 20 $\mu \mathrm{l} / \mathrm{min}$. The $1 \mu \mathrm{m}$ microparticles remain dispersed under all flow conditions without the elastic effect. $5 \mu \mathrm{m}$ microparticles starts to be focused weakly when flow rate reaches $20 \mu \mathrm{l} / \mathrm{min}$ due to the increasing inertial effects. In viscoelastic fluid, the particles are affected by both the elastic and inertial effects, and particles with different sizes can be focused and separated according to their blockage ratio, while in Newtonian fluid the particles cannot be separated decently by the pure effect of inertial forces. This indicates that the elastic effect plays an important role in efficient particle separation.
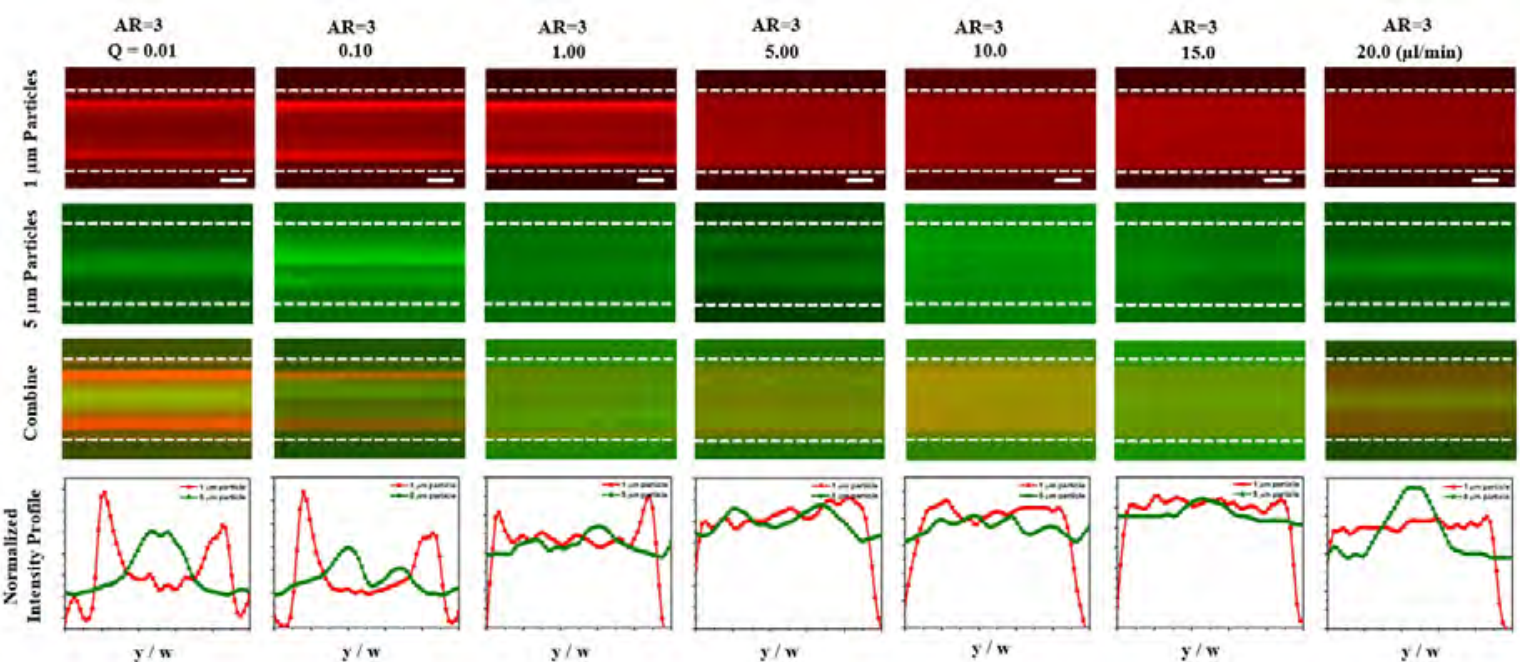

Figure 3 Trajectories of the 1 and $5 \mu \mathrm{m}$ fluorescent microparticles in Newtonian fluid in straight microchannel with $\mathrm{AR}=3$. The first and second rows are the individual fluorescent trajectories of $1 \mu \mathrm{m}$ and $5 \mu \mathrm{m}$ particles. The third row is combined fluorescent trajectories of both microparticles. The fourth row is their normalized intensity profiles. The scale bars $=10 \mu \mathrm{m}$.

\section{Effect of aspect ratio of the microchannel}

In order to investigate the effects of aspect ratio in straight channels, the particle distribution in straight rectangular channel with cross section of $50 \mu \mathrm{m} \times 10 \mu \mathrm{m}$ (width $\times$ height) (Figure 4 (a), $\mathrm{AR}=5$ ) and $100 \mu \mathrm{m} \times 10 \mu \mathrm{m}$ (width $\times$ height) (Figure 4 (b) $\mathrm{AR}=10$ ) in the same viscoelastic fluid was studied. In straight channel with an aspect ratio of $A R=5$, the $1 \mu \mathrm{m}$ 
fluorescent microparticles $(\beta=0.06)$ can be focused at the center area of the channel, but with a much wider focusing width. Meanwhile, the $5 \mu \mathrm{m}$ fluorescent microparticles $(\beta=0.3)$ migrate to both the centre and channel walls although its blockage ratio has exceed $0.25(0.01 \mu \mathrm{l} / \mathrm{min}$ $\leq Q \leq 10 \mu \mathrm{l} / \mathrm{min})$. One reason may be due to its blockage ratio does not exceed the threshold value much, therefore, the two sidewall migration phenomenon is not as obvious as that $A R=3$. On the other side, this may be explained by the blunted velocity profile along the channel width. As the width of the channel becomes wider, velocity distribution along the width becomes increasingly flat. The fluid shear rate is very small along a large central area. Therefore, when they were displaced from the centerline, the shear rate was not intensified enough to induce a strong normal stress difference to drive all of the particles towards the sidewalls. From this perspective, the particle migration in viscoelastic fluid is not only affected by blockage ratio, but also affected by aspect ratio of microchannel. As the flow rate increases further $(Q>10$ $\mu \mathrm{l} / \mathrm{min}$ ), the inertial effect starts to be dominant, the equilibrium positions at the two channel walls becomes not stable, leaving a single wide focusing band at the central area for $5 \mu \mathrm{m}$ microparticles.

Similar with particle distribution in the straight channel with aspect ratio $\mathrm{AR}=5$, in the straight channel with aspect ratio $\mathrm{AR}=10,1 \mu \mathrm{m}$ microparticles $(\beta=0.05)$ distributed in a larger center area. For $5 \mu \mathrm{m}$ microparticles $(\beta=0.27)$, a small portion of microparticles are focused on the two channel walls, most of them confined in the wide central band. By comparison, it indicates that the channel with $\mathrm{AR}=3$ yields best separation performance. 
(a)
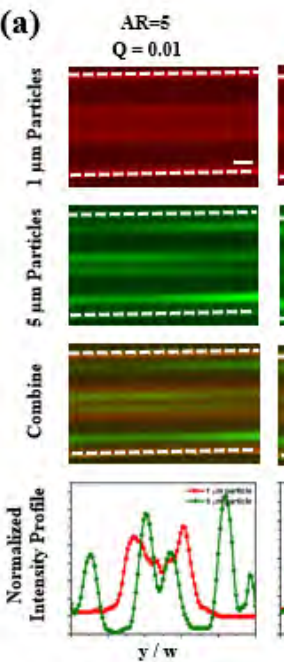

(b)
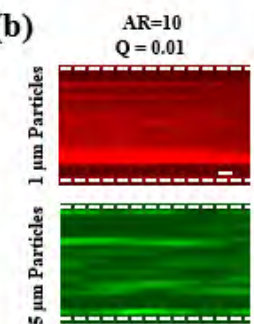

ปั
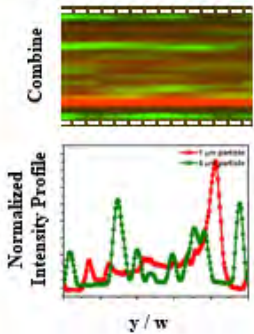
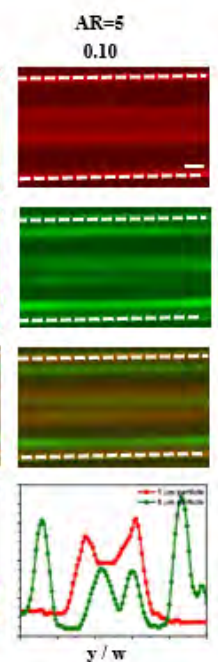

$A R=10$

0.10
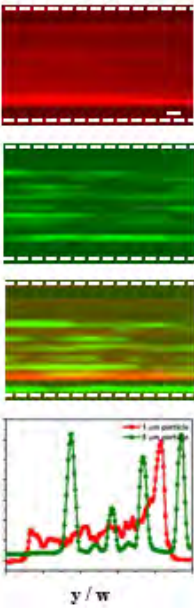
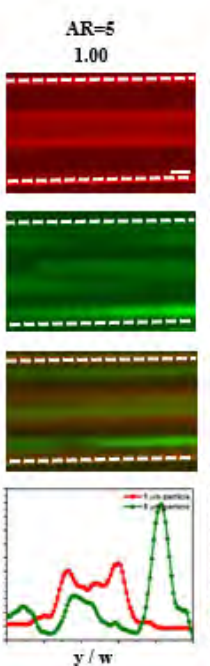

$\mathrm{AR}=10$

1.00
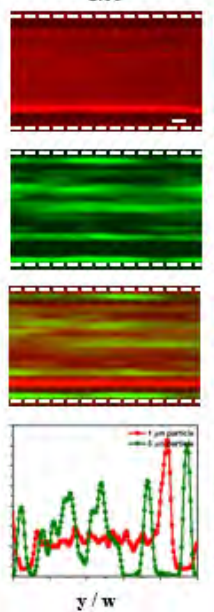
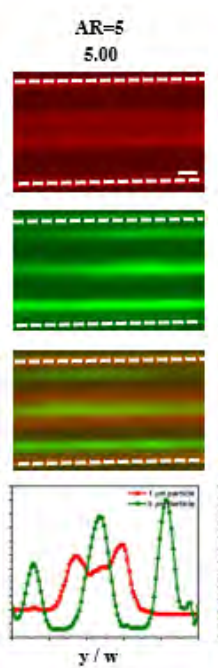

$A R=10$

5.00
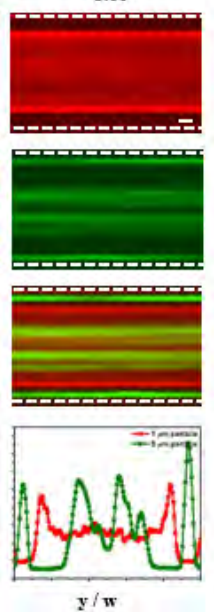
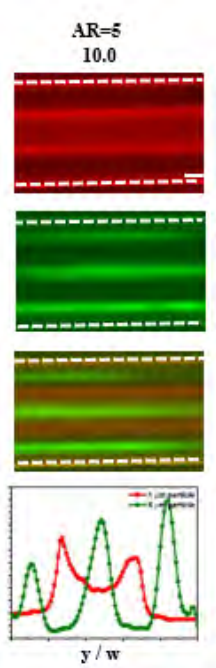

$\mathrm{AR}=10$
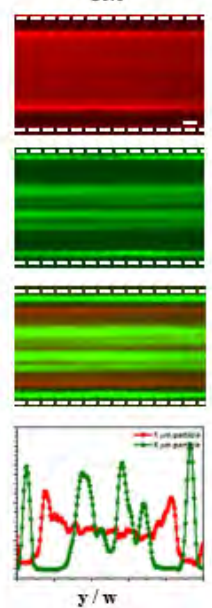
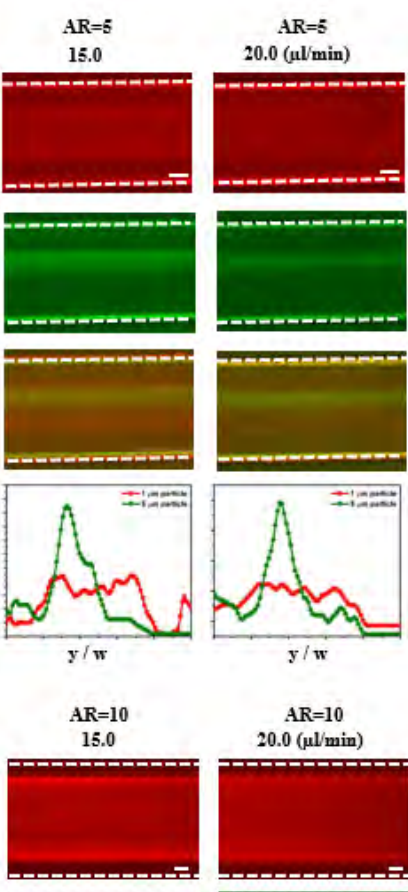

$\mathrm{AR}=10$ $20.0(\mu \mathrm{l} / \mathrm{min})$
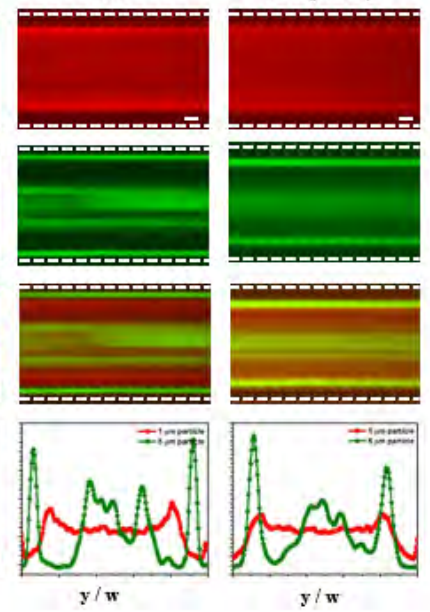

Figure 4 Trajectories of the 1 and $5 \mu \mathrm{m}$ fluorescent microparticles in viscoelastic fluid in straight microchannel with $\mathrm{AR}=5$ (a) and $\mathrm{AR}=10$ (b) at outlet at different flow rates, respectively. (a) The first, second, third, and fourth row show the trajectories of the $1 \mu \mathrm{m}$ fluorescent microparticles, $5 \mu \mathrm{m}$ fluorescent microparticles, combination of both $1 \mu \mathrm{m}$ and $5 \mu \mathrm{m}$ particles, normalized intensity profiles of both $1 \mu \mathrm{m}$ and $5 \mu \mathrm{m}$ fluorescent microparticles at the outlet of the straight microchannel at flow rates ranging from 0.01 to $20 \mu \mathrm{l} / \mathrm{min}$. (b) Similar to (a), the first, second, third, and fourth row show the trajectories of the $1 \mu \mathrm{m}$ fluorescent microparticles, $5 \mu \mathrm{m}$ fluorescent microparticles, combination of both $1 \mu \mathrm{m}$ and $5 \mu \mathrm{m}$ particles, normalized intensity profiles of both $1 \mu \mathrm{m}$ and 5 $\mu \mathrm{m}$ fluorescent microparticles at the outlet of the straight microchannel at flow rates ranging from 0.01 to 20 $\mu \mathrm{l} / \mathrm{min}$, respectively. The scale bars $=10 \mu \mathrm{m}$.

\section{Microparticle separation performance}

Figure 5 (a) shows the superimposed experimental image of the lateral focusing positions for

$1 \mu \mathrm{m}$ and $5 \mu \mathrm{m}$ fluorescent microparticles at $Q=1 \mu \mathrm{L} / \mathrm{min}$ in viscoelastic fluid in straight microchannel with $\mathrm{AR}=3$. It can be seen that the $1 \mu \mathrm{m}$ microparticles are focused in the centre and flow out from Outlet 2 , while $5 \mu \mathrm{m}$ microparticles are focused on two sides of the channel 
and flow out from Outlet 1 and Outlet 3. The fluorescent images for $1 \mu \mathrm{m}, 5 \mu \mathrm{m}$, combination of $1 \mu \mathrm{m}$ and $5 \mu \mathrm{m}$ fluorescent microparticles at inlet, outlet 1, outlet 2, and outlet 3 (Figure 5(b)) can verify the separation performance. In the inlet, the particles are mixed; in outlet 1 and outlet 3 , we can only see $5 \mu \mathrm{m}$ microparticles, with almost all the $1 \mu \mathrm{m}$ microparticles being eliminated; while only the $1 \mu \mathrm{m}$ microparticles can be seen in outlet 2 . The percentage was calculated as the number of $1 \mu \mathrm{m}$ or $5 \mu \mathrm{m}$ particle in each outlet with respect to its total amount at the three outlets, Figure 5(c). The percentage of $1 \mu \mathrm{m}$ microparticles at the outlets 1 and 3 is quite low ( $0.57 \%$ and $1.15 \%$ respectively), which means almost all the $1 \mu \mathrm{m}$ microparticles are collected by the outlet 2 (percentage $98.28 \%$ in outlet 2), corresponding to the removal ratio of $1 \mu \mathrm{m}$ particles in Figure 5 (d). The percentage of $5 \mu \mathrm{m}$ microparticles in outlet 1 and 3 is $34.38 \%$ and $59.38 \%$ respectively, corresponding to the separation efficiency of $5 \mu \mathrm{m}$ particles $(93.76 \%)$ in Figure 5 (d), which indicates a low loss of $5 \mu \mathrm{m}$ microparticles. These results demonstrated that this device can separate particles based on their sizes with a high removal ratio of untargeted particles and a high separation efficiency of targeted particles. 
(a)

(b)

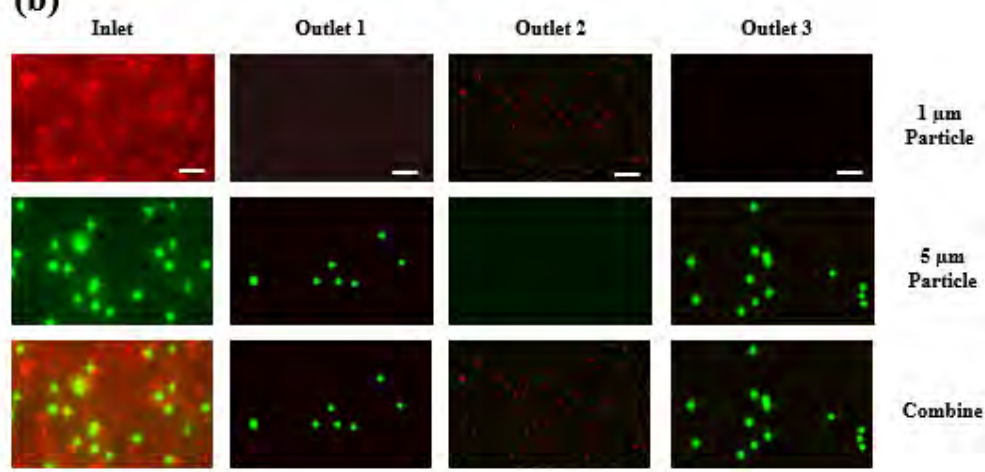

(c)

(d)
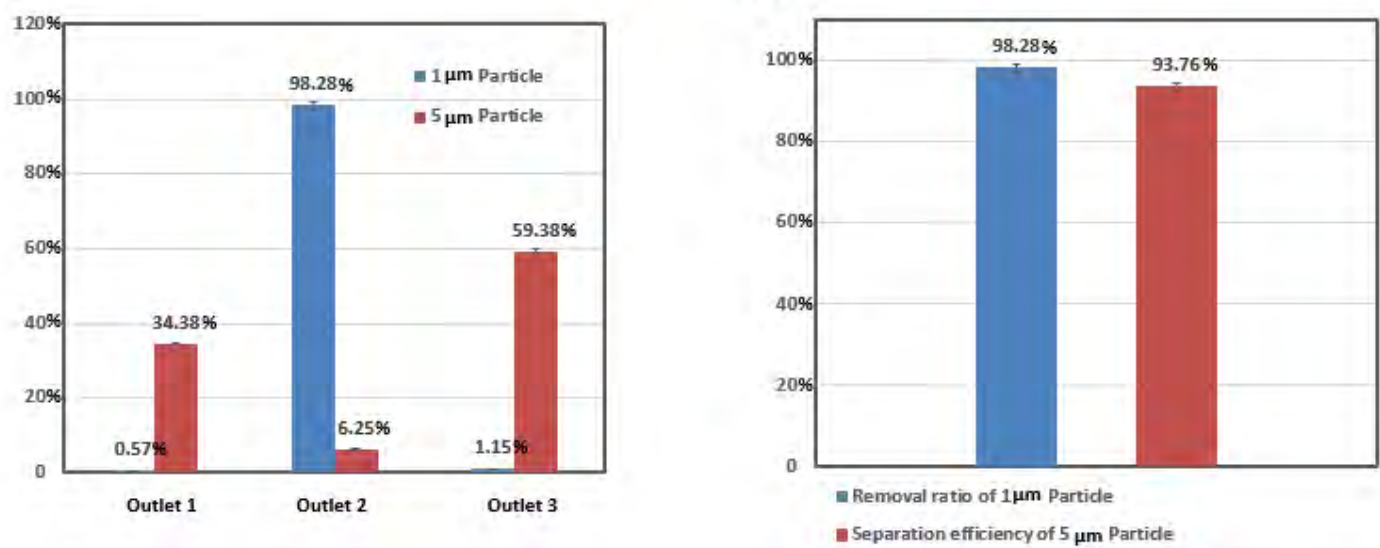

Figure 5. (a) Superimposed experimental image showing the lateral focusing positions for $1 \mu \mathrm{m}$ and $5 \mu \mathrm{m}$ fluorescent microparticles at $\mathrm{Q}=1 \mu \mathrm{L} / \mathrm{min}$ in viscoelastic fluid in straight microchannel with $\mathrm{AR}=3$. Scale bar $=$ $20 \mu \mathrm{m}$. (b) Fluorescent images for $1 \mu \mathrm{m}, 5 \mu \mathrm{m}$, combination of $1 \mu \mathrm{m}$ and $5 \mu \mathrm{m}$ fluorescent microparticles at inlet, outlet 1 , outlet 2, and outlet 3, respectively. Scale bar $=20 \mu \mathrm{m}$. (c) Percentage of $1 \mu \mathrm{m}$ and $5 \mu \mathrm{m}$ fluorescent microparticles at outlets 1-3, respectively. The percentage was considered as the number of $1 \mu \mathrm{m}$ or $5 \mu \mathrm{m}$ particle in each outlet with respect to its total amount at the three outlets. (d) Removal ratio of $1 \mu \mathrm{m}$ particle, separation efficiency of $5 \mu \mathrm{m}$ particles. Removal ratio of $1 \mu \mathrm{m}$ particles, considered as the percentage of $1 \mu \mathrm{m}$ particles in outlet 2 with respect to the total amount of $1 \mu \mathrm{m}$ particles found at the three outlets. The separation efficiency was calculated as the percentage of $5 \mu \mathrm{m}$ particles found in outlet 1 and outlet 3 with respect to the total amount of 5 $\mu \mathrm{m}$ particles found at the three outlets.

\section{Separation of microalgae and bacteria}

Based on the optimum flow rates obtained using the fluorescent microparticles, similar tests were conducted with microalgae cells and bacteria. The diameter of microalgae Chlorella is about $5 \mu \mathrm{m}$ in diameter, and the equivalent diameter of Bacillus Subtilis is about $1 \mu \mathrm{m}$ in diameter. The tested flow rates were from 0.01 to $5 \mu 1 / \mathrm{min}$. Figure 6 (a) shows the trajectories of microalgae cells and bacteria in viscoelastic fluid in the straight microchannel with $A R=3$, 
respectively. The red circles indicate the microalgae cells, and the blue arrows indicate the bacteria. When the flow rate is lower than $5 \mu \mathrm{l} / \mathrm{min}$, the microalgae cells are focused on two sides of the channel walls, while the bacteria are focused at the channel centre, which is in agreement with that of the mimicking fluorescent microparticles. However, unlike the focusing of standard spherical polystyrene microparticles, when the flow rate reaches $5 \mu \mathrm{l} / \mathrm{min}$, both the microalgae cells and bacteria begin to disperse. It is presumed that the cell deformability, heterogeneity and the non-sphericity of the bacteria is the underlying cause. These results also indicate that $Q=1 \mu \mathrm{L} / \mathrm{min}$ is the optimal flow rate to maximize separation of microalgae and bacteria, which is in agreement with the tests using the standard microparticles.

Figure 6b (i) shows the trajectories of microalgae cells and bacteria under the flow rate of $1 \mu \mathrm{l} / \mathrm{min}$. Figures $6 \mathrm{~b}$ (ii-iv) are the images of microalgae cells and bacteria at outlet 1 , outlet 2 , and outlet 3 , respectively. In outlet 1 and outlet 3 , we can see most are microalgae cells, with only a few bacteria; while only the bacteria can be seen in outlet 2 . The bacteria in outlet 1 and outlet 3 can be fully eliminated by recirculation processes under the same conditions. Besides, the percentage of microalgae and bacteria at the three outlets were calculated respectively (Figure 6 (c)). The percentage was calculated as the number of target cells (microalgae or bacteria) in each outlet with respect to its total amount at the three outlets. The percentage of bacteria in outlet 1 and outlet 3 is quite low (3.14\% and 3.89\% respectively), which means almost all of the bacteria are separated to outlet 2 (92.97\% in outlet 2$)$, corresponding to removal ratio of bacteria (92.97\%) in Figure 6 (d). The percentage of microalgae in outlet 2 is $0 \%$, which means all of microalgae are recovered by outlets 1 and 3 (38.46\% and $61.54 \%$ in outlet 1 and outlet 3 respectively), corresponding to the 100\% separation efficiency in Figure 6 (d). These results demonstrated that this device can separate microalgae and bacteria based on their sizes with a high removal ratio of bacteria and a high separation efficiency of microalgae. 

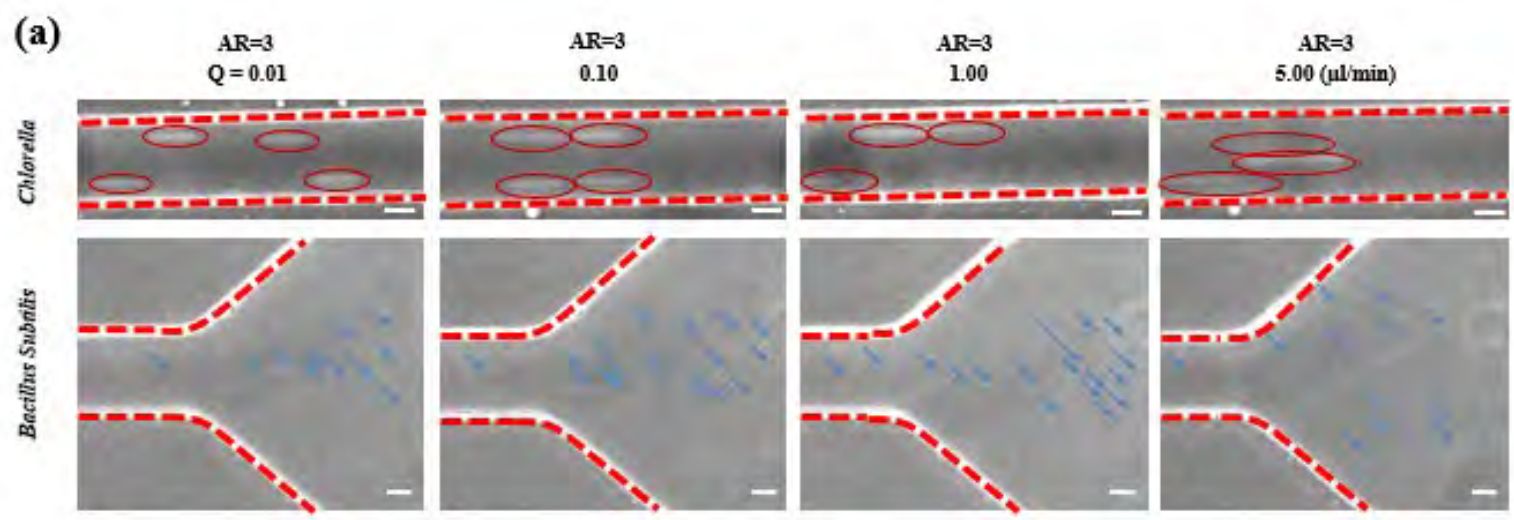

(b)

Outlet 1
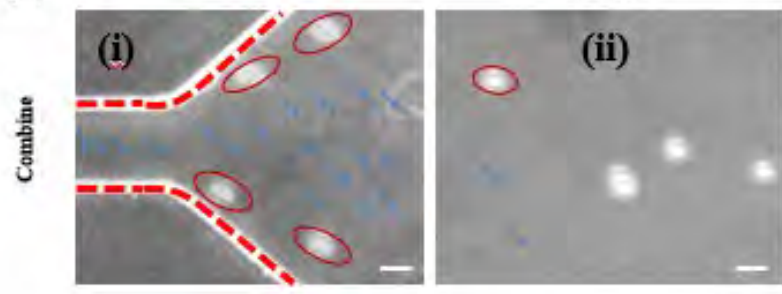

(c)

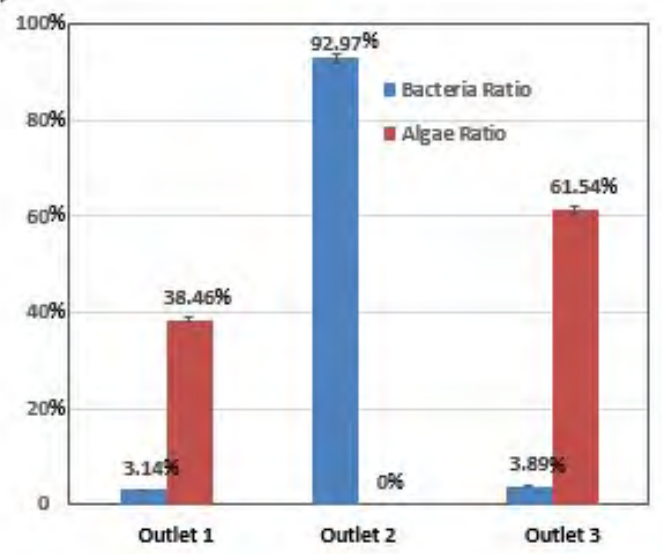

(d)

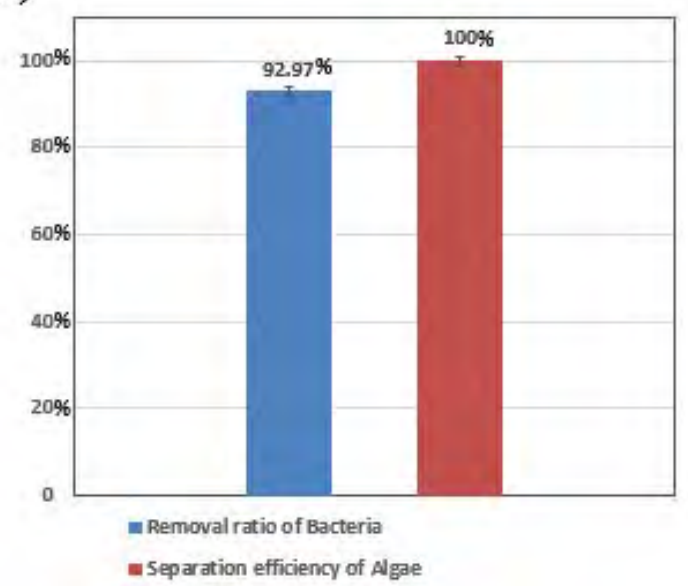

Figure 6. Trajectories of microalgae cells and bacteria in viscoelastic fluid in straight microchannel with AR=3. (a) First row: Trajectories of the microalgae cells at the outlet of the straight microchannel at flow rates ranging from 0.01 to $5 \mu \mathrm{l} / \mathrm{min}$. Second row: Trajectories of the bacteria under the same conditions. (b) The first image shows the combined trajectories of microalgae cells and bacteria in viscoelastic fluid in straight microchannel with $\mathrm{AR}=3$ under the flow rate of $1 \mu \mathrm{l} / \mathrm{min}$. Others are images for combination of microalgae cells and bacteria at outlet 1, outlet 2, and outlet 3, respectively. Scale bar $=10 \mu \mathrm{m}$. (c) Percentage of microalgae cells and bacteria at outlet 1 , outlet 2 , and outlet 3 , respectively. The percentage was considered as the number of microalgae cells or bacteria in each outlet with respect to its total amount at the three outlets. (d) Removal ratio of bacteria, separation efficiency of microalgae cells. Removal ratio of bacteria, was considered as the percentage of bacteria in outlet 2 with respect to the total amount of bacteria found at the three outlets. The separation efficiency was calculated as the percentage of microalgae cells found in outlet 1 and outlet 3 with respect to the total amount of microalgae found at the three outlets. 


\section{Concluding remarks}

In this work, we have successfully demonstrated the sheathless separation of microalgae from contaminating bacteria using a simple straight channel based on viscoelastic microfluidics. It allows for larger microalgae migrating to the channel walls, while confining smaller bacteria focused in the channel center. We systematically studied the effects of flow rates and channel length, fluid viscoelasticity, and the channel aspect ratio. At the optimum flow condition, up to $92.97 \%$ of the bacteria were removed from the culture, while also $100 \%$ microalgae cells were recovered. For further reduction of contaminating bacteria, serial repeating of the separation processes is an efficient strategy. Overall, this study should open up a new, simple method for microalgae separation from bacteria. Since the separation principle is based on the differential viscoelastic separation, which is related to the size of the particles, this method may be extended to other similar samples such as separating bacteria from other microalgae cells, separating microalgae with different species, or separation of mammalian cells as well. 


\section{Acknowledgements}

This work is supported by the Australian Research Council (ARC) Discovery Project (Grant No. DP180100055), the National Natural Science Foundation of China (Grant No.51705257) and the Natural Science Foundation of Jiangsu Province (Grant No. BK20170839). Dr. Sheng Yan gratefully acknowledges the support of the Japan Society for the Promotion of Science (JSPS).

The authors have declared no conflict of interest. 


\section{References}

[1] Pamme, N., Lab Chip 2007, 7, 1644-1659.

[2] Sajeesh, P., Sen, A. K., Microfluid Nanofluid 2014, 17, 1-52.

[3] Gossett, D. R., Weaver, W. M., Mach, A. J., Hur, S. C., Tse, H. T. K., Lee, W., Amini, H., Di Carlo, D., Anal Bioanal Chem 2010, 397, 3249-3267.

[4] Juang, Y. J., Chang, J. S., Biotechnology journal 2016, 11, 327-335.

[5] Yu, Z. T. F., Aw Yong, K. M., Fu, J., Small 2014, 10, 1687-1703.

[6] Nagrath, S., Sequist, L. V., Maheswaran, S., Bell, D. W., Irimia, D., Ulkus, L., Smith, M. R., Kwak, E. L., Digumarthy, S., Muzikansky, A., Nat. 2007, 450, 1235-1239.

[7] Bhagat, A. A. S., Bow, H., Hou, H. W., Tan, S. J., Han, J., Lim, C. T., Med Biol Eng Comput 2010, 48, 999-1014.

[8] Laurell, T., Petersson, F., Nilsson, A., Chemical Society Reviews 2007, 36, 492-506.

[9] Yan, S., Zhang, J., Alici, G., Du, H., Zhu, Y., Li, W., Lab Chip 2014, 14, 2993-3003.

[10] Kang, Y., Li, D., Kalams, S. A., Eid, J. E., Biomed. Microdevices 2008, 10, 243-249.

[11] Glückstad, J., Nature Materials 2004, 3, 9-10.

[12] Pamme, N., Wilhelm, C., Lab Chip 2006, 6, 974-980.

[13] Yamada, M., Nakashima, M., Seki, M., Anal. Chem. 2004, 76, 5465-5471.

[14] Di Carlo, D., Irimia, D., Tompkins, R. G., Toner, M., Proc Nat Acad Sci 2007, 104, 18892-18897.

[15] Zhang, J., Yan, S., Sluyter, R., Li, W., Alici, G., Nguyen, N.-T., Sci Rep 2014, 4.

[16] Zhang, J., Yan, S., Yuan, D., Alici, G., Nguyen, N.-T., Warkiani, M. E., Li, W., Lab Chip 2016, 16, 10 34.

[17] Huang, L. R., Cox, E. C., Austin, R. H., Sturm, J. C., Science 2004, 304, 987-990.

[18] Moorthy, J., Beebe, D. J., Lab Chip 2003, 3, 62-66.

[19] Choi, S., Park, J.-K., Lab Chip 2007, 7, 890-897.

[20] D'Avino, G., Romeo, G., Villone, M. M., Greco, F., Netti, P. A., Maffettone, P. L., Lab Chip 2012, $12,1638-1645$.

[21] Yang, S., Kim, J. Y., Lee, S. J., Lee, S. S., Kim, J. M., Lab Chip 2011, 11, 266-273.

[22] Del Giudice, F., Romeo, G., D'Avino, G., Greco, F., Netti, P. A., Maffettone, P. L., Lab Chip 2013, $13,4263-4271$.

[23] Seo, K. W., Byeon, H. J., Huh, H. K., Lee, S. J., RSC Adv 2014, 4, 3512-3520.

[24] Li, D., Lu, X., Xuan, X., Anal. Chem. 2016, 88, 12303-12309.

[25] Liu, C., Xue, C., Chen, X., Shan, L., Tian, Y., Hu, G., Anal. Chem. 2015, 87, 6041-6048.

[26] Yang, S. H., Lee, D. J., Youn, J. R., Song, Y. S., Anal. Chem. 2017, 89, 3639-3647.

[27] Kang, K., Lee, S. S., Hyun, K., Lee, S. J., Kim, J. M., Nat. Commun 2013, 4, 2567.

[28] Lim, E. J., Ober, T. J., Edd, J. F., Desai, S. P., Neal, D., Bong, K. W., Doyle, P. S., McKinley, G. H., Toner, M., Nat. Commun 2014, 5, 4120.

[29] Nam, J., Lim, H., Kim, D., Jung, H., Shin, S., Lab Chip 2012, 12, 1347-1354.

[30] Yuan, D., Zhang, J., Sluyter, R., Zhao, Q., Yan, S., Alici, G., Li, W., Lab Chip 2016, 16, 3919-3928.

[31] Zhang, J., Yan, S., Yuan, D., Zhao, Q., Tan, S. H., Nguyen, N.-T., Li, W., Lab Chip 2016, 16, $3947-$ 3956.

[32] Yuan, D., Zhang, J., Yan, S., Pan, C., Alici, G., Nguyen, N.-T., Li, W., Biomicrofluidics 2015, 9, 044108.

[33] Liu, C., Guo, J., Tian, F., Yang, N., Yan, F., Ding, Y., Wei, J., Hu, G., Nie, G., Sun, J., ACS nano 2017, 11 6968-6976.

[34] Yuan, D., Tan, S. H., Zhao, Q., Yan, S., Sluyter, R., Nguyen, N.-T., Zhang, J., Li, W., RSC Adv 2017, 7, 3461-3469.

[35] Yuan, D., Tan, S. H., Sluyter, R., Zhao, Q., Yan, S., Nguyen, N.-T., Guo, J., Zhang, J., Li, W., Anal. Chem. 2017, 89, 9574-9582.

[36] Liu, C., Ding, B., Xue, C., Tian, Y., Hu, G., Sun, J., Anal. Chem. 2016, 88, 12547-12553.

[37] D'Avino, G., Greco, F., Maffettone, P. L., Annu Rev Fluid Mech 2017, 49, 341-360.

[38] Yuan, D., Zhao, Q., Yan, S., Tang, S.-Y., Alici, G., Zhang, J., Li, W., Lab Chip 2018, 18, 551-567. 
[39] Wan, C., Alam, M. A., Zhao, X.-Q., Zhang, X.-Y., Guo, S.-L., Ho, S.-H., Chang, J.-S., Bai, F.-W., Bioresource technology 2015, 184, 251-257.

[40] Schenk, P. M., Thomas-Hall, S. R., Stephens, E., Marx, U. C., Mussgnug, J. H., Posten, C., Kruse, O., Hankamer, B., Bioenergy research 2008, 1, 20-43.

[41] Searchinger, T., Heimlich, R., Houghton, R. A., Dong, F., Elobeid, A., Fabiosa, J., Tokgoz, S., Hayes, D., Yu, T.-H., Science 2008, 319, 1238-1240.

[42] Spolaore, P., Joannis-Cassan, C., Duran, E., Isambert, A., Journal of bioscience and bioengineering 2006, 101, 87-96.

[43] Cantrell, K. B., Ducey, T., Ro, K. S., Hunt, P. G., Bioresource technology 2008, 99, 7941-7953.

[44] Chisti, Y., Biotechnology advances 2007, 25, 294-306.

[45] Schaap, A., Rohrlack, T., Bellouard, Y., Lab Chip 2012, 12, 1527-1532.

[46] Song, Y., Li, M., Yang, J., Wang, J., Pan, X., Sun, Y., Li, D., Sensor Actuat B-chem 2014, 194, 164172.

[47] Wang, J., Sun, J., Song, Y., Xu, Y., Pan, X., Sun, Y., Li, D., Sensors 2013, 13, 16075-16089.

[48] Li, M., Muñoz, H., Schmidt, A., Guo, B., Lei, C., Goda, K., Di Carlo, D., Lab Chip 2016, 16, 44584465.

[49] Schaap, A., Rohrlack, T., Bellouard, Y., Journal of biophotonics 2012, 5, 661-672.

[50] Deng, Y.-L., Chang, J.-S., Juang, Y.-J., Bioresource technology 2013, 135, 137-141.

[51] Schaap, A., Dumon, J., Den Toonder, J., Microfluid Nanofluid 2016, $20,125$.

[52] Au, S. H., Shih, S. C., Wheeler, A. R., Biomed. Microdevices 2011, 13, 41-50.

[53] Dewan, A., Kim, J., McLean, R. H., Vanapalli, S. A., Karim, M. N., Biotechnol Bioeng 2012, 109, 2987-2996.

[54] Paik, S.-M., Sim, S.-J., Jeon, N. L., Bioresource technology 2017, 233, 433-437.

[55] Lee, A. K., Lewis, D. M., Ashman, P. J., Biomass and bioenergy 2012, 46, 89-101.

[56] Günerken, E., d'Hondt, E., Eppink, M., Garcia-Gonzalez, L., Elst, K., Wijffels, R., Biotechnology advances 2015, 33, 243-260.

[57] Hønsvall, B. K., Altin, D., Robertson, L. J., Bioresource technology 2016, 200, 360-365.

[58] Syed, M. S., Rafeie, M., Henderson, R., Vandamme, D., Asadnia, M., Warkiani, M. E., Lab Chip 2017, 17, 2459-2469.

[59] Milledge, J. J., Heaven, S., Reviews in Environmental Science and Bio/Technology 2013, 12, 165178.

[60] Han, A., Hou, H., Li, L., Kim, H. S., de Figueiredo, P., Trends in biotechnology 2013, 31, 225-232.

[61] Heaney, S., Jaworski, G., British Phycological Journal 1977, 12, 171-174.

[62] Cellamare, M., Rolland, A., Jacquet, S., Journal of applied phycology 2010, 22, 87-100.

[63] Koch, R., Mittheil kais Gesundheitsamte 1881, 1, 1-48.

[64] Andersen, R. A., Algal culturing techniques, Elsevier 2005.

[65] Sinigalliano, C. D., Winshell, J., Guerrero, M. A., Scorzetti, G., Fell, J. W., Eaton, R. W., Brand, L., Rein, K. S., 2009.

[66] Godino, N., Jorde, F., Lawlor, D., Jaeger, M., Duschl, C., J Micromech Microeng 2015, 25, 084002.

[67] Syed, M. S., Rafeie, M., Vandamme, D., Asadnia, M., Henderson, R., Taylor, R. A., Warkiani, M.

E., Bioresource technology 2018, 252, 91-99.

[68] Huang, P., Feng, J., Hu, H. H., Joseph, D. D., J Fluid Mech. 1997, 343, 73-94.

[69] Feng, J., Huang, P., Joseph, D., J Non-newtonian Fluid Mech 1996, 63, 63-88.

[70] Asmolov, E. S., J Fluid Mech. 1999, 381, 63-87.

[71] Di Carlo, D., Lab Chip 2009, 9, 3038-3046.

[72] Magda, J., Lou, J., Baek, S., DeVries, K., Polymer 1991, 32, 2000-2009.

[73] Pathak, J. A., Ross, D., Migler, K. B., Phys. Fluids 2004, 16, 4028-4034.

[74] Lu, X., Liu, C., Hu, G., Xuan, X., J Colloid Interface Sci 2017, 500, 182-201.

[75] Sollier, E., Murray, C., Maoddi, P., Di Carlo, D., Lab Chip 2011, 11, 3752-3765.

[76] McDonald, J. C., Whitesides, G. M., Account Chem Res 2002, 35, 491-499. 